\title{
A PARTILHA DE INFORMAÇÃO COM FAMILIARES EM UNIDADE DE TRATAMENTO INTENSIVO: IMPORTÂNCIA ATRIBUIIDA POR ENFERMEIROS
}

Elisabete Saiote ${ }^{1}$, Felismina Mendes ${ }^{2}$

\begin{abstract}
RESUMO: Perante o internamento do doente numa unidade de terapia intensiva, os familiares desejam obter informação e procuram o enfermeiro, o qual cada vez mais se centra em atividades de "lifesaving". O presente estudo analisa o posicionamento dos enfermeiros de uma unidade de terapia intensiva sobre a importância da partilha de informação entre enfermeiros e familiares de doentes internados. Trata-se de estudo exploratório e descritivo, utilizando como instrumentos de coleta de dados a entrevista semiestruturada a doze enfermeiros. A análise dos dados permitiu concluir que os enfermeiros ignoram as necessidades da família relativas à comunicação, colocando-as em segundo plano na sua esfera de prioridades; na sua prática, predominam atividades tecnicistas valorizadas pela profissão. Os profissionais justificam a fuga à comunicação com o excesso de trabalho e a falta de tempo. Identificaram-se também como fatores limitadores da comunicação as características inerentes à unidade de terapia intensiva e às dificuldades do processo comunicativo.
\end{abstract}

PALAVRAS-CHAVE: Informação; Comunicação; Família; Enfermagem.

\section{THE SHARING OF INFORMATION AMONG FAMILIES IN AN INTENSIVE THERAPY UNIT: IMPORTANCE ATTRIBUTED BY NURSES}

ABSTRACT: Faced with the hospitalisation of a patient in an intensive therapy unit, family members wish to obtain information and ask the nurses, who are increasingly centred in 'lifesaving' activities. This study analyses the position of nurses from an intensive therapy unit on the importance of sharing information with members of the families of patients interned in their units. It is an exploratory and descriptive study, with data collected via semi-structured interviews with twelve nurses. Data analysis permitted the conclusion that nurses ignore the needs of families concerning communication, placing it low down among their priorities; in their practice, technical activities valued by their profession predominate. The health professionals justify the failure to communicate on grounds of work load and shortage of time. Characteristics intrinsic to intensive therapy units and difficulties in the communicative process were also identified as factors hindering communication.

KEYWORDS: Information; Communication; Family; Nursing.

\section{COMPARTIR INFORMACIÓN CON FAMILIARES EN UNIDAD DE TRATAMIENTO INTENSIVO: IMPORTANCIA ATRIBUIDA POR ENFERMEROS}

RESUMEN: Delante del internamiento del enfermo en una unidad de terapia intensiva, los familiares desean obtener información y buscan al enfermero, quien cada vez más se concentra en actividades de "lifesaving". El presente estudio analiza el posicionamiento de los enfermeros de una unidad de terapia intensiva sobre la importancia de compartir información entre enfermeros y familiares de enfermos internados. Este es un estudio exploratorio y descriptivo, que utilizó como instrumentos para recoger datos la entrevista semiestructurada a doce enfermeros. El análisis de los datos permitió concluir que los enfermeros ignoran las necesidades de la familia acerca de la comunicación, poniéndolas en segundo plan en su esfera de prioridades; en su práctica, predominan actividades tecnicistas valoradas por la profesión. Los profesionales justifican la falta de comunicación con el exceso de trabajo y la escasez de tiempo. Fueron identificados también como factores limitadores de la comunicación las características inherentes a la unidad de terapia intensiva y a las dificultades del proceso comunicativo. PALABRAS CLAVE: Información; Comunicación; Familia; Enfermería.

${ }^{1}$ Enfermeira da Unidade de Cuidados Intensivos do Hospital de São Bernardo, Setubal - Portugal. Mestre em Sociologia da Saúde e da Doença. ${ }^{2}$ Enfermeira. Doutora em Sociologia. Professora Coordenadora do Departamento de Enfermagem da Universidade de Évora. Pesquisadora do Instituto Universitário de Lisboa - Portugal.

Autor correspondente:

Felismina Mendes

Instituto Universitário de Lisboa

Av. Defensores de Chaves, 2 - 1000-117 - Lisboa-Portugal

Recebido: 02/03/11

E-mail: fm@uevora.pt

Aprovado: 13/05/11

Cogitare Enferm. 2011 Abr/Jun; 16(2):219-25 


\section{INTRODUÇÃO}

Nas últimas décadas o desenvolvimento científico e tecnológico aplicado à saúde tem promovido o uso de técnicas de diagnóstico e terapêuticas decisivas na recuperação de doentes. As Unidades de Tratamento Intensivo (UTI) são exemplo de serviços especializados funcionando com pessoal treinado, e equipadas com material sofisticado resultante da mais avançada tecnologia. Isto lhes confere uma distinção entre outros serviços de atenção à saúde.

Nestas unidades observa-se uma integração minuciosa da prestação de cuidados, do ensino e da investigação. São também serviços dotados de regras e princípios de funcionamento próprios onde se pode identificar protocolos específicos para cada intervenção; todos os cuidados são prestados com o máximo de rigor e perfeccionismo, obedecendo a métodos de trabalho organizados e aliciantes ${ }^{(1)}$.

Aliado aos benefícios da disponibilidade constante e imediata de recursos tecnológicos nas UTI, existe o fator ansiedade que o aparato tecnológico transmite ao doente e família. Todos os recursos necessários para garantir a estabilidade do doente exigem, muitas vezes, técnicas invasivas (instalação de drenos, sondas, cateteres e tubos) as quais são percebidas pela família como causadoras de dor e desconforto físico e emocional. Elas geram, além disso, nos prórpios familiares, medo e elevado grau de incerteza no que concerne ao diagnóstico, tratamento e, sobretudo, prognóstico. Assim, os familiares vêem-se obrigados a obter informação junto dos profissionais, de modo que esses os ajudem a entender o que se passa com o doente, para definir e redefinir seus objetivos de vida, fazer planos com conhecimento de causa, obter serenidade, tranquilidade e segurança, em vez de conjecturar com base em medos e angústias ${ }^{(2-3)}$.

Deste modo, é usual observar-se, durante o internamento, uma procura desesperada de informação junto aos enfermeiros, por parte da família. De acordo com o ponto 6 da Carta dos Deveres e Direitos dos Doentes, estes têm o direito de serem informados sobre a situação de sua saúde. O direito à informação não pertence apenas ao doente, mas também aos familiares que, durante o internamento, passam ser portadores dos direitos do doente ${ }^{(4)}$.

A comunicação entre enfermeiro e familiar é um importante instrumento para manter a família informada sobre a realidade do doente, para explicar os procedimentos realizados e seus objetivos, os motivos da existência de determinadas regras e normas de conduta; é uma ação que se revela, portanto, fundamental no envolvimento e participação do familiar nos cuidados.

Tanto os doentes como a família desejam manter-se informados; quando esta informação não pode ser pormenorizada, uma simples explicação sobre procedimentos básicos e horários ajuda-os a manter a calma, diminuindo os sentimentos de medo e ansiedade experienciados ${ }^{(4)}$.

No entanto, é usual observar nas UTI, por parte do enfermeiro, uma falta de iniciativa em procurar o familiar do doente para lhe facultar informações, sendo clara a dificuldade que estes profissionais têm em interagir com a família. Segundo autores ${ }^{(5)}$, os enfermeiros que exercem sua prática profissional em UTI continuam a centrar esforços na manutenção das funções vitais do doente e no cumprimento da totalidade das rotinas, após as quais, não lhes resta tempo para outras ações. Eles sentem-se satisfeitos por terem executado todas as técnicas de forma adequada e conferem importância secundária aos cuidados à família, com a qual mantêm uma relação demasiado distante. Estes profissionais de saúde tendem a "objetificar" o doente/familiares recorrendo às rotinas do serviço, a tratamentos e burocratização de processos, fornecendo informação escassa e pouco objetiva ${ }^{(6)}$.

Quando os cuidados de enfermagem são prestados num ambiente que exige alta tecnicidade, o cuidar corre o risco de se tornar um mero procedimento mecanicista. No entanto, para outros autores, os enfermeiros valorizam a participação dos familiares na recuperação dos doentes e atribuem, como valor adicional ao tratamento, a presença do familiar. Assim, flexibilizam algumas rotinas da unidade para que esse contato ocorra sempre que possível $^{(7)}$.

Apesar disso, verifica-se que os enfermeiros dedicam-se, de forma muito limitada, aos familiares, esquecendo que eles são parte integrante da socialização do doente. Os profissionais justificam a sua atitude com o fato de terem dificuldades em saber quais as verdadeiras necessidades de informação dos doentes/familiares, alegando também carência de qualificação e falta de experiência no processo comunicacional ${ }^{(6)}$. Também o fator tempo, que eles afirmam, com frequencia, não dispor 
devido à sobrecarga de trabalho, impossibilita-os de refletir e praticar as técnicas de comunicação.

Neste contexto esta pesquisa teve como objetivo central analisar o posicionamento dos enfermeiros de uma UTI sobre a importância da partilha de informação entre os enfermeiros e os familiares dos doentes internados.

\section{METODOLOGIA}

Tendo em consideração o problema de investigação, optou-se pela metodologia qualitativa, através da realização de um estudo exploratório e descritivo, a partir de uma amostra intencional constituída por enfermeiros que desempenhavam funções em UTI há pelo menos dois anos e, igualmente, com uma experiência profissional superior a dois anos.

Como instrumento de coleta de informação foi utilizada a entrevista semiestruturada, esta foi gravada após obtenção do consentimento dos enfermeiros e da autorização da direção do hospital. A entrevista semiestruturada seguiu um guia estruturado a partir de quatro categorias analíticas (desempenhar funções numa UTI, a comunicação na prática de enfermagem, a comunicação entre enfermeiros e familiares numa UTI e a necessidade de formação no âmbito da comunicação e das relações interpessoais) e o período de realização ocorreu entre julho e setembro de 2009. Para a análise de dados, utilizou-se a técnica da análise de conteúdo seguindo os procedimentos propostos por $\mathrm{Carmo}^{(8)}$.

Todos os procedimentos inerentes à coleta $\mathrm{e}$ análise de dados respeitaram os princípios constantes na Declaração de Helsink (1975 e revisada em 1983).

\section{RESULTADOS}

Os doze enfermeiros participantes apresentaram idades compreendidas entre 28 e 47 anos, perfazendo uma média de 36 anos; tinham entre 2 e 22 anos de exercício profissional, com uma média 13,3 anos; o tempo de exercício profissional em UTI variou entre 2 e 15 anos, perfazendo uma média de 7,8 anos. Os participantes foram codificados como $\mathrm{E} 1, \mathrm{E} 2, \ldots . ., \mathrm{E} 12$.

A análise de conteúdo do corpus das entrevistas permitiu estabelecer três categorias, as quais deram origem a várias subcategorias, como se pode observar no quadro 1.

Quadro 1 - Categorias de análise das entrevistas. Portugal, 2009

\begin{tabular}{|c|c|}
\hline CATEGORIAS & SUBCATEGORIAS \\
\hline \multirow{4}{*}{ Desempenhar funções numa UTI } & Especificidades dos cuidados \\
\hline & Competências exigidas \\
\hline & Formação contínua \\
\hline & Motivação \\
\hline \multirow[t]{2}{*}{ Importância da informação na prática de enfermagem } & Centralidade incontornável \\
\hline & Disponibilidade e dedicação \\
\hline \multirow{4}{*}{ Comunicação entre enfermeiros e familiares numa UTI } & $\mathrm{O}$ internamento \\
\hline & Necessidades de apoio e informação \\
\hline & Postura e atitudes \\
\hline & Fuga à comunicação \\
\hline
\end{tabular}

\section{DISCUSSÃO}

Com relação à categoria Desempenhar funções numa UTI verificou-se que os enfermeiros entrevistados partilham a opinião de alguns autores ${ }^{(9)}$ quando caracterizam a UTI como um serviço diferenciado, onde existe uma especificidade de cuidados que torna o trabalho desenvolvido diferente daquele que é realizado nas enfermarias. Na UTI, o trabalho é considerado mais complexo, mais intenso, mais exigente e de maior rigor, não só no contexto técnico como também dos cuidados prestados ao doente. O enfermeiro necessita assumir uma vigilância constante, redobrando a sua atenção em tudo o que executa e reajustando, simultaneamente, as suas intervenções de acordo com a evolução do doente. Sobre isso, assim se manifestou um entrevistado:

No geral, uma unidade de cuidados intensivos requer outro nível de competências, outro nível de conheci- 
mentos, temos que ter uma abordagem múltipla por assim dizer, porque uma repercussão em algo pode ter um problema de base. Pode ter um problema de base que não é aquele que diretamente repercute essa alteração. Temos que ter, temos que ter a capacidade rápida de contextualizar isso e rapidamente responder, e nas enfermarias, teoricamente, temos algum tempo para responder. E aqui, não. (E6)

É fundamental que o enfermeiro saiba interpretar a informação que a tecnologia lhe transmite, associá-la ao estado do doente e saber atuar, sendo esta interpretação e esta habilidade apenas adquiridas quando se trabalha diariamente e ao fim de algum tempo nestes serviços ${ }^{(1)}$. De fato, para estes enfermeiros dominarem o componente tecnicista, estarem munidos de conhecimentos científicos e atualizados e, desta forma, preparados para manusear equipamentos cada vez mais sofisticados, de modo a responder imediatamente a todas as exigências com que diariamente se deparam, é um desafio constante.

Todos os entrevistados consideraram deter os conhecimentos necessários ao trabalho na UTI e competências específicas, diferenciadas daquelas que são necessárias ao trabalho nas enfermarias. Os entrevistados defenderam que muitos dos conhecimentos que possuem apenas foram adquiridos por exercerem funções em UTI.

[...] temos que ter conhecimentos que os outros não têm, como por exemplo, trabalhar com ventiladores. Como fazemos hemodiálise e técnica dialítica continua pronto, logo ai temos mais conhecimentos do que os outros enfermeiros [...] também temos mais algum conhecimento em termos de traçados cardíacos do que aqueles das enfermarias que não têm doentes, que têm esporadicamente doentes monitorizados, mas isto é inerente ao sítio onde estamos. (E11)

De acordo com os enfermeiros, o conhecimento adquirido na graduação parece ser suficiente para trabalhar na enfermaria, mas é considerado escasso para prestar cuidados numa UTI. Consideram, no entanto, que o trabalho na enfermaria proporciona oportunidade de aprofundar e adquirir um corpo de conhecimentos gerais que lhes confere competências em várias áreas e lhes permite, a priori, trabalhar em serviços diferenciados, como uma UTI.

Desta forma, é necessário associar a formação básica e a experiência profissional à formação contínua.
Uma formação complexa como a enfermagem pressupõe uma formação que permita ao profissional desenvolver um conjunto de competências científicas e técnicas sendo essencial reconhecer simultaneamente a importância das dimensões existências, relacionais e efectivas $^{(10: 236)}$.

Para melhorar o seu desempenho profissional e a qualidade dos cuidados prestados, estes enfermeiros procuram atualizar os seus conhecimentos assistindo a cursos, reuniões científicas e desenvolvendo ações de formação no próprio local de trabalho.

Verificou-se que, para a maioria dos enfermeiros entrevistados, trabalhar na UTI era um objetivo profissional e pessoal a ser atingido rapidamente em sua trajetória profissional. A diversidade de patologias, as inúmeras situações críticas, a constante instabilidade do doente, o domínio pericial da tecnologia de ponta, as mudanças de atuação contínuas, de doente para doente, o prognóstico permanentemente reservado e a elevada rotatividade de doentes (que leva à não-rotinização de trabalho) são considerados fatores que influenciam a satisfação e bem-estar dos enfermeiros na UTI.

$\mathrm{Na}$ categoria A importância da informação na prática de enfermagem verificou-se que, conceitualmente, os entrevistados consideram que a comunicação assume uma centralidade incontornável na prática de enfermagem, é um processo ubíquo e contínuo no local de trabalho e um dos pilares dessa prática. Para estes enfermeiros, a comunicação não engloba apenas o diálogo entre enfermeiro/doente, mas sim, o diálogo com todos os intervenientes (médicos, outros enfermeiros, doentes, familiares, técnicos de exames complementares de diagnóstico), assumindo um papel primordial na continuidade dos cuidados

De fato, os enfermeiros são um elo entre doente e família, uma vez que são os profissionais de saúde que permanecem mais tempo junto do doente e aqueles que estão melhor posicionados para dialogar e informar a família sobre o estado do doente ${ }^{(11)}$.

No entanto, para alguns entrevistados, mais importante do que estabelecer um diálogo com a família e fornecer informação, é demonstrar disponibilidade e dedicação, pois muitos familiares apenas procuram apoio para ultrapassar o momento difícil em que se encontram.

Em relação a família, acho que é muito importante não só, não só uma comunicação [...]. Às vezes é mais importante nós mostrarmos disponibilidade para a pessoa do que estarmos com aquela explicação exaus- 
tiva sobre o que se está a passar com o doente [...] eles assimilam mais se calhar nós mostrarmos dedicação e disponibilidade. (E12)

São vários os enfermeiros que consideraram a família, neste processo de comunicação, não só como um elemento que necessita de ajuda, mas sim, como alguém que, por vezes, pode ajudar o enfermeiro a entender o comportamento, as angústias e o medo do doente. Desse modo, torna-se fundamental inseri-la como parceira no processo de cuidados; a família pode colaborar com o enfermeiro na decodificação de mensagens que o doente, por vezes, não consegue verbalizar, revelando-se uma mais-valia na relação entre o doente e o enfermeiro. Apesar do fornecimento de informação fazer parte das competências do profissional de enfermagem, e dos enfermeiros entrevistados estarem cientes da sua importância no processo de cuidados, foram muitos aqueles que, por razões que não conseguiam explicitar, assumiram não ter as habilidades comunicacionais requeridas para conseguir operacionalizá-la de acordo com o que é preconizado conceitualmente.

$\mathrm{Na}$ categoria Comunicação entre enfermeiros e familiares numa UTI os enfermeiros referiram existir, na sociedade atual, uma conotação negativa quando se fala do internamento numa UTI. Para muitos indivíduos estas unidades são sinônimo de sofrimento e morte, onde impera a tecnologia e não há lugar para uma relação mais próxima entre doentes/familiares e enfermeiros, o que afeta a comunicação.

Nestes serviços, onde impera um ambiente peculiar e diferente, caracterizado como "estranho" e "agressivo", o medo do desconhecido domina. Os diferentes elementos da família ficam assim envolvidos num emaranhado de sentimentos como raiva, perda, luto antecipado, sofrimento, desespero, ansiedade, distúrbios de humor, elevado nível de estresse e dificuldade em lidar com a situação. Por meio do discurso dos entrevistados verificou-se que estes enfermeiros têm a noção da "cascata" de emoções experienciadas pelos familiares e afirmam ser essencial conceber estas famílias como pessoas que necessitam de apoio, informação e ajuda. A transmissão de informação não apenas reduz os níveis de ansiedade e de estresse, mas ajuda os membros da família a estabelecer esperança realista e aumentar as reservas de energia, habitualmente despendidas em elevado grau nestes internamentos ${ }^{(12)}$. De acordo com os entrevistados, não é necessário transmitir informações exaustivas aos familiares para tranquilizá-los, bastam informações simples, como explicar o estado global e o quadro clínico do doente, a finalidade da medicação realizada e a função de cada um dos equipamentos ao qual o doente está conetado:

A unidade é um mundo à parte daquele que as pessoas geralmente estão habituadas e que conhecem e nós temos que nos por um bocado da parte deles, do lado deles [...] acho que a comunicação aqui com os familiares, acho que é muito importante o apoio que podemos dar aos familiares, é muito importante. Dou um bocadinho de apoio, acho que as pessoas gostam de sentir apoio porque eles estão perdidos. (E11)

No processo de comunicação entre enfermeiros e familiares na UTI a postura e as atitudes adotadas pelo enfermeiro perante os familiares (a sua forma de estar, a forma como se dirige, ouve, responde as questões colocadas, esclarece as dúvidas) são igualmente importantes para o início de uma relação comunicativa. Todos os enfermeiros entrevistados verbalizaram que, para se iniciar a relação enfermeiro/família e apaziguar os sentimentos experienciados pelos membros da família, é fundamental realizar um acolhimento eficiente ao familiar. O enfermeiro deve identificar-se, abordar o familiar logo na entrada do serviço, acompanhá-lo até o doente, explicar-lhe as normas e rotinas do serviço, o porquê de determinados procedimentos, a tecnologia usada no doente e a sua finalidade, e refortalecer a ideia de que estas unidades são contextos em que a atenção para com o doente é redobrada.

Apesar de todos os enfermeiros, durante as entrevistas, terem demonstrado valorizar o processo comunicativo e o considerarem como uma das suas obrigações profissionais, por vezes acionam estratégias de fuga à comunicação, essencialmente durante o horário nobre de atendimento dos familiares - o horário da visita. A equipe de enfermagem não exige o cumprimento rigoroso deste, permitindo o acesso e permanência de familiares para além do horário estabelecido. Estes enfermeiros têm atitude correta pois, ao permitirem a flexibilização no horário da visita e a permanência do familiar junto do doente, facilitam não só o contato entre familiar e doente, mas também o desenvolvimento do processo de comunicação ${ }^{(13)}$.

Foram muitos os enfermeiros que referiram ser "obrigados" a dedicar o período da visita não só aos familiares mas, essencialmente, a aproveitar o tempo disponível para executar e finalizar as tarefas que não conseguiram terminar durante todo o turno. 
[...] às vezes acaba por ser na hora da visita que nós conseguimos ter mais disponibilidade para as nossas coisas. Não quer dizer que a comunicação não seja importante com as familias. É muito importante, mas, às vezes, há que estabelecer prioridades, às vezes é necessário preparar as medicações nesta hora e não temos outra hora para o fazer e acaba por ser "roubada" a hora dos familiares [...]. (E9)

A preocupação com os aspectos administrativos do cuidado consome parte significativa das horas de trabalho do enfermeiro, gerando falta de tempo para que estes fomentem o processo comunicativo ${ }^{(14)}$. Contudo, a qualidade da informação depende, essencialmente, das habilidades de quem fala e do tempo despendido com o processo de comunicação ${ }^{(15)}$.

A atitude perante os membros de família, durante a visita, varia de enfermeiro para enfermeiro, e para alguns entrevistados a disponibilidade que têm para dedicar à família não depende apenas do trabalho e do tempo, mas sobretudo da personalidade, formação, sensibilização, bom senso e percepção que cada profissional tem acerca da importância que a partilha de informação entre enfermeiro/família assume.

\section{[...] e depois depende da sensibilidade do enfermeiro} que está e do bom senso para se aproximar, ou não, $e$ para ter um tipo de conversa melhor, ou pior [...]. (E6)

De fato, a comunicação entre enfermeiro e familiar numa UTI é um processo que, quando é estabelecido, sofre inúmeras interrupções relacionadas à própria dinâmica do serviço. Destaca a constante atenção que os doentes requerem, a execução contínua de procedimentos, a estabilização hemodinâmica e elétrica do doente e os apelos constantes do médico ou de um alarme que toca. Todos estes fatores influenciam o tipo de diálogo desenvolvido, uma vez que, independentemente das causas da interrupção, quando esta situação ocorre, é raro que o diálogo seja restabelecido, havendo mesmo algumas situações em que a comunicação é dada por terminada.

Porém, mais que o ambiente de determinado contexto e as intercorrências que o caracterizam, a experiência profissional é um fator que pode influenciar o processo de comunicação, pois os anos de exercício profissional fornecem ao enfermeiro habilidades e competências para estar mais atento às reações dos familiares, quando existe a necessidade de lhes ser comunicada uma má notícia ${ }^{(16)}$.

\section{CONSIDERAÇÕES FINAIS}

A ambição e motivação para desempenhar funções numa UTI prende-se muitas vezes com a realização profissional, pois é nestes serviços, onde impera a tecnologia, que os enfermeiros adquirem elevado nível de conhecimentos. Também, nesse ambiente, eles colocam em prática e desenvolvem as competências que adquiriram ao longo do seu percurso acadêmico e profissional, desenvolvendo um conjunto de atividades que os torna diferenciados e socialmente valorizados.

Os enfermeiros entrevistados consideram o trabalho desenvolvido na UTI como dinâmico e complexo; afirmam desempenhar um conjunto de atividades que requerem alto nível de exigência, atenção minuciosa e habilidades intelectuais e psicomotoras bastante desenvolvidas, fatores que lhes conferem um grau mais tecnicista e mecanicista. A necessidade de atualização que lhes permita acompanhar o desenvolvimento tecnológico e científico, é uma exigência permanente no cotidiano destes enfermeiros.

Eles consideram que a comunicação e a partilha de informação assumem uma centralidade incontornável na prática de enfermagem, quer no trabalho com os pares, quer com os doentes e familiares, pois só desta forma conseguem assegurar a continuidade e a qualidade da prestação de cuidados. A comunicação e a partilha de informação com a família são valorizadas pelos enfermeiros, os quais consideram-nas pilar da Enfermagem.

Porém, as concepções expressas também revelam que, escudados nos procedimentos técnicos e nas intervenções especializadas, esses profissionais tendem a ignorar as necessidades da família e a relegar esta competência profissional para um plano secundário na sua esfera de prioridades. Ou seja, eles revelam grandes dificuldades na operacionalização do processo comunicativo com os familiares. Os próprios enfermeiros entrevistados reconhecem e admitem desvalorizar a importância da esfera comunicacional na prática cotidiana. $\mathrm{O}$ excesso de trabalho e a falta de tempo emergem como as justificativas apontadas para a secundarização da comunicação com os familiares. No entanto, os pretextos mencionados parecem ser antes uma forma de os enfermeiros justificarem a sua fuga à comunicação.

Conclui-se que, apesar de todos os enfermeiros reconhecerem a importância em dialogar, esclarecer, orientar e apoiar os membros de família, estas atividades ainda não são reconhecidas como prioritárias, 
dando lugar às atividades mecanicistas e tecnicistas, tão características das UTI e fortemente associadas à valorização profissional e social dos enfermeiros.

\section{REFERÊNCIAS}

1. Carapinheiro G. Saberes e poderes no hospital: uma sociologia dos serviços hospitalares. Porto: Edições Afrontamento; 1993.

2. Bettinelli L. Cuidado solidário. Lisboa: Pé Berthier; 1998.

3. Sheehy S. Enfermagem de urgência. Loures: Lusociência; 2001.

4. Zussman R. Intensive care: medical ethic and the medical profession. Chicago: The University of Chicago Press; 1992.

5. Kosco M, Warren N. Critical care nurses perceptions of family needs as met. CCN. 2000;23(2):60-72.

6. Dias M. A esmeralda perdida: a informação prestada ao doente oncológico. Lisboa: Climepsi Editores; 2005.

7. Pinho L. O cuidado de enfermagem na unidade de terapia intensiva. Rev Esc Enferm USP. 2008;42(1):62-72.

8. Hermano-Carmo MMF. Metodologia da investigação: guia para auto-aprendizagem. Lisboa: Editor Universidade Aberta; 1998.

9. Lopes N. A recomposição profissional da enfermagem: estudo sociológico em contexto hospitalar. Coimbra: Quarteto; 2001.

10. Fabião A, Magano CO, Ferreira JM, Miranda PR. Formação: contributo para a qualidade. Servir. 2005;53(5):236-43.

11. Mitchell ML, Courtney M, Coyer F. Understanding uncertainty and minimizing families' anxiety at the time of transfer from intensive car. Nurse Health Sci. 2003;(5):207-17.

12. Verhaeghe S, Van Zuuren F, Defloor T, Duijnstee MSH, Grypdonck MHF. How does information influence hope in family members of traumatic coma patients in intensive care unit? J Clin Nurs. 2007;16(3):1488-97.

13. Knobel E. Condutas no paciente grave. São Paulo: Atheneu; 2006.
14. Siqueira B, Filipini R, Posso MBS, Fiorano AMM, Gonçalves SA. Relacionamento enfermeiro, paciente e família: factores comportamentais associados à qualidade da assistência. Arq Med ABC. 2006;31(2):737.

15. Silva ÉE, Campos LF. Passagem de plantão na enfermagem: revisão da literatura. Cogitare Enferm. 2007;12(4):502-7.

16. Ferreira A, Fontes A. Do outro lado da porta... falar com a família numa unidade de cuidados intensivos. Sinais Vitais. 2009;85(7):35-8. 